\title{
Humic substances: from structure to application through plant action mechanism
}

Baigorri R. ${ }^{1,2}$, Urrutia O. ${ }^{2}$, Erro J. ${ }^{2}$, San Francisco S. ${ }^{1}$, García-Mina J.M. ${ }^{2}$

${ }^{1}$ Timac Agro, Orkoien, Spain. roberto.baigorri@timacagro.es

${ }^{2}$ University of Navarra, Pamplona, Spain

Keywords: structure, application, fertilization

doi: 10.36291/HIT.2019.baigorri

Humic substances (HS) are the Organic Matter component in soils that connect the mineral phase with the vegetation cover. Like an interphase connecting the no-living and the living world through a huge quantity of chemical and biochemical reactions. And this marvelous ecological role is possible because of the high versatility of HS.

We previously describe the HS adaptability to different soils (acidic, alkaline, sodic, saline...) in relation to the structural complexity in function to these soil characteristics. Thus Gray, Brown or Fulvic fraction, showed different molecular arrangement and structure. And how humification is an ordered and no randomness process in which composting is a very early step. In a biological point of view, we described the hormonal mechanism in which HS are involved when are in contact to plants promoting development and growth in both root and shoot.

Finally, here we show the applicability of $\mathrm{HS}$ in the manufacturing of different products:

1. a solid granulated fertilizer, in which a humic phase was applied to a sulphatephosphate matrix yielding the previously anion-metal humic complexes described in soils,

2. a humic based iron chelate protected by a second organic molecule (Fig. 1) to prevent the collapse of iron humate and,

3. livestock humic-feed in two different phosphate phases as monocalcium and dicalcium are, yielding phosphate-calcium-humate bounds in function of their different $\mathrm{pH}$ and crystallographic cell.

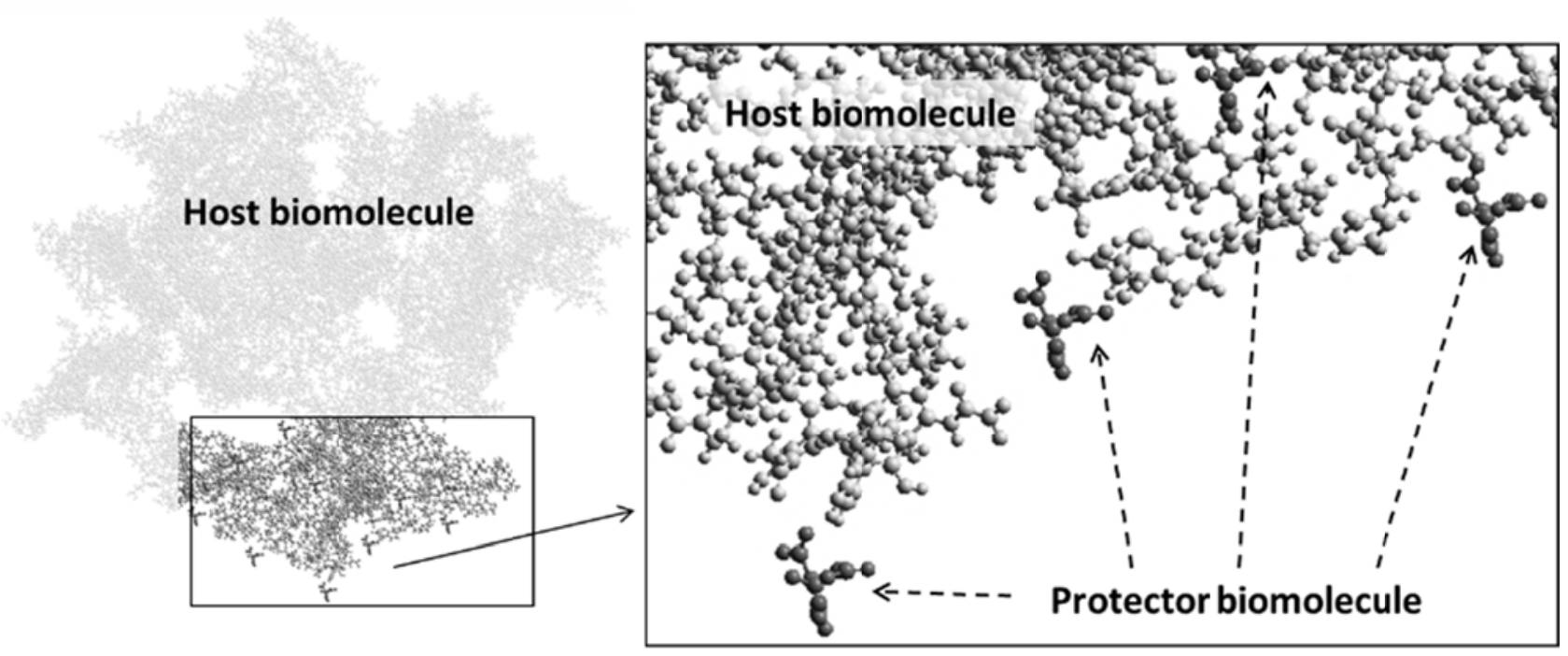

Figure 1. Humic-iron chelate protected by a second organic molecule. 